\title{
ESPÉCIES PREDOMINANTES NA DEPOSIÇÃO DE SERAPILHEIRA EM FRAGMENTO DE FLORESTA ESTACIONAL DECIDUAL NO RIO GRANDE DO SUL
}

\author{
DOMINANT SPECIES IN LITTER DEPOSITION IN A SEASONAL DECIDUOUS FOREST \\ FRAGMENT IN RIO GRANDE DO SUL STATE
}

\author{
Mauro Valdir Schumacher ${ }^{1}$ Peter Trüby ${ }^{2} \quad J$ seane Marian Marafiga ${ }^{3}$ \\ Márcio Viera ${ }^{4}$ Denise Andréia Szymczak ${ }^{5}$
}

\begin{abstract}
RESUMO
Objetivou-se avaliar a deposição total de serapilheira e das principais espécies encontradas na Floresta Estacional Decidual no município de Itaara, RS. Foram utilizados 30 coletores metálicos de formato circular alocados em seis parcelas. O material depositado foi coletado mensalmente entre janeiro de 2006 a dezembro de 2007. A serapilheira foi separada nas frações folhas, galhos finos (diâmetro $<0,5 \mathrm{~cm}$ ) e miscelânea (flores, frutos, sementes e restos vegetais não identificáveis). Além disso, as folhas foram separadas de acordo com as espécies mais representativas da floresta e as demais foram classificadas como “outras". A deposição média anual de serapilheira foi de 5,85 $\mathrm{Mg} \mathrm{ha}^{-1} \mathrm{ano}^{-1}$, sendo composta por $63,2 \%$ de folhas, 19,6\% de miscelânea e 17,1\% de galhos finos. Parapiptadenia rigida, Ocotea pulchella e Matayba elaeagnoides, foram responsáveis por cerca de 30\% da deposição total de serapilheira. A deposição de folhas da Lithraea molleoides, Cupania vernalis, Nectandra megapotamica e Matayba elaeagnoides aumentaram significativamente com o aumento da pluviosidade e a da Parapiptadenia rigida com a diminuição da temperatura do ar.
\end{abstract}

Palavras-chave: espécies nativas; material orgânico; sustentabilidade florestal.

\begin{abstract}
This study had as objective to evaluate litter total deposition and litter from main species from Seasonal Deciduous Forest, in Itaara, RS. Thirty circular metal collectors were allocated in six plots. The litter was collected monthly, from January 2006 to December 2007. The litter was separated in leaves, thin branches (diameter $<0.5 \mathrm{~cm}$ ) and miscellany (flowers, fruits, seeds and non identified plants). The leaves were separated considering the most representative species in the forest and the others were classified as "others". The average annual litter deposition was $5.85 \mathrm{Mg} \mathrm{ha}^{-1}$ year"-1, composed $63.2 \%$ of leaves, $19.6 \%$ of miscellany and $17.1 \%$ of thin branches. Parapiptadenia rigida, Ocotea pulchella and Matayba elaeagnoides were responsible for about 30\% from total litter deposition. The leaves deposition of Lithraea molleoides, Cupania vernalis, Nectandra megapotamica and Matayba elaeagnoides increased significantly when rainfall increased and Parapiptadenia rigida increased when the air temperature decreased.
\end{abstract}

Keywords: native species; organic material; forest sustainability.

1. Engenheiro Florestal, Dr., Professor Associado do Departamento de Ciências Florestais, Centro de Ciências Rurais, Universidade Federal de Santa Maria, Av. Roraima, 1000, CEP 97105-900, Santa Maria (RS). Bolsista CNPq.mvschumacher@gmail.com

2. Engenheiro Florestal, Dr., Professor do Institut für Bodenkunde und Waldernährungslehre, Albert-LudwigsUniversität, Freiburg, Alemanha. peter.trueby@bodenkunde.uni-freiburg.de

3. Engenheira Florestal, Universidade Federal de Santa Maria, Av. Roraima, 1000, CEP 97105-900, Santa Maria (RS). josemarafiga@yahoo.com.br.

4. Engenheiro Florestal, Doutorando do programa de Pós-graduação em Engenharia Florestal, Centro de Ciências Rurais, Universidade Federal de Santa Maria, Av. Roraima, 1000, CEP 97105-900, Santa Maria (RS). Bolsista CNPq. vieraflorestal@yahoo.com.br

5. Mestranda do Programa de Pós-graduação em Engenharia Florestal, Centro de Ciências Rurais, Universidade Federal de Santa Maria, Av. Roraima, 1000, CEP 97105-900, Santa Maria (RS). Bolsista CAPES. deniseximi@yahoo.com.br

Recebido para publicação em 19/02/2010 e aceito em 11/06/2010 


\section{INTRODUÇÃO}

Atualmente, as florestas do estado do Rio Grande do Sul encontram-se em um avançado processo de alteração de sua forma original e primitiva. Segundo Longhi et al. (1999), a devastação da floresta em grande parte foi causada por uma exploração intensiva de espécies de interesse madeireiro, a qual, com o posterior avanço das fronteiras agrícolas culminou na derrubada de grande parte destas florestas, reduzindo-as a fragmentos, comprometendo, desta forma, a diversidade biológica e a conservação destes ecotipos florestais.

A Floresta Estacional Decidual, em seus estágios iniciais, médios e avançados de sucessão ocupa, no estado do Rio Grande do Sul, uma área de $11.762,45 \mathrm{~km}^{2}$, o que representa $4,16 \%$ da superfície do estado e $23,84 \%$ da área total coberta com florestas naturais (RIO GRANDE DO SUL, 2002). É uma das formações florestais mais importantes do estado, em termos de localização geográfica, área ocupada e de histórico cultural, sendo poucas as informações que se tem sobre este ecossistema (CUNHA, 1997), principalmente sobre a capacidade produtiva, que está intimamente relacionada ao processo de ciclagem de nutrientes através da deposição de serapilheira.

O estudo da deposição de serapilheira em florestas nativas é um dos aspectos primordiais para a avaliação da nutrição mineral e ciclagem de nutrientes nesses ecossistemas, com vistas ao planejamentodo uso destasespécies para recuperação de áreas degradadas ou para produção de madeiras nobres (POGGIANI e SCHUMACHER, 2004).

Essa serapilheira constitui-se na camada de detritos vegetais (folhas, ramos, caules, cascas, frutos e flores) e animais dispostos na superfície do solo, contribuindo, juntamente com os demais compartimentos florestais, para a interceptação da água da chuva, e seu armazenamento no solo, para o aumento das taxas de infiltração e condicionamento dos fluxos superficiais (OLSON, 1963; OLIVEIRA FILHO, 1987). A quantidade depositada varia em função da tipologia vegetal e da condição climática. Vários fatores, abióticos e bióticos, afetam a produção de serapilheira, como tipo de vegetação, altitude, latitude, precipitação, temperatura, regimes de luminosidade, relevo, deciduidade, estágio sucessional, disponibilidade hídrica e características do solo (FIGUEIREDO FILHO et al., 2003).

Em uma vasta compilação de literatura sobre a deposição de serapilheira em diferentes florestas do mundo, Bray e Ghoran (1964) concluíram que, de modo geral, são compostas de $60-80 \%$ por folhas, de $12-15 \%$ por ramos, de $1-15 \%$ por frutos e de $1-15 \%$ por cascas de árvores e que florestas situadas em regiões árticas ou alpinas produzem anualmente cerca de uma tonelada por hectare de serapilheira, florestas temperadas frias 3,5 toneladas, florestas temperadas quentes 5,5 toneladas e florestas equatoriais cerca de 11 toneladas.

No entanto, pouco se conhece, sobre a composição dessa serapilheira, em relação a quais espécies são mais representativas na deposição e em quais períodos do ano. Segundo Vogel (2005), dependendo da composição de espécies arbóreas de uma floresta, haverá uma maior ou menor deposição de serapilheira e consequentemente uma maior ou menor aporte de nutrientes na floresta. Neste contexto, o trabalho objetivou avaliar a deposição total de serapilheira e das principais espécies encontradas na Floresta Estacional Decidual no município de Itaara, RS.

\section{MATERIAL E MÉTODOS}

\section{Localização da área de estudo}

$\mathrm{O}$ estudo foi realizado em um fragmento de Floresta Estacional Decidual no município de Itaara, RS (Figura 1), estando situado nas coordenadas geográficas centrais de $29^{\circ} 30^{\prime}$ de latitude Sul e $53^{\circ} 46^{\prime}$ de longitude Oeste, possuindo uma altitude média de 400 metros em relação ao nível do mar.

Segundo a classificação climática de Köppen, a região possui clima tipo subtropical úmido, com variedade climática $\mathrm{Cfa}$, caracterizada pela ocorrência de chuvas durante todos os meses do ano (MORENO, 1961), registrando temperatura máxima média de $25,8{ }^{\circ} \mathrm{C}$ e temperatura média mínima de $13{ }^{\circ} \mathrm{C}$, com precipitação variando entre 1.700 e 1.800 milímetros anuais (AGRITEMPO, 2010). O solo é do tipo Neossolo Litólico eutrófico típico, com textura média, relevo forte ondulado e substrato basáltico, apresentando uma sequência de horizontes $\mathrm{A} / \mathrm{R}$ e com profundidade média em torno de $35 \mathrm{~cm}$ (STRECK et al., 2008).

$\mathrm{Na}$ área experimental em estudo, Longhi e Greff (2006) encontraram com maior frequência as espécies arbóreas: Allophylus edulis (A. St.-Hil., Cambess. \& A. Juss.) Radlk., Caliandra tweediei Benth., Cupania vernalis Cambess., Dalbergia frutescens (Vell.) Britton, Eugenia hyemalis Cambess., Helietta apiculata Benth., Lithraea

Ci. Fl., v. 21, n. 3, jul.-set., 2011 


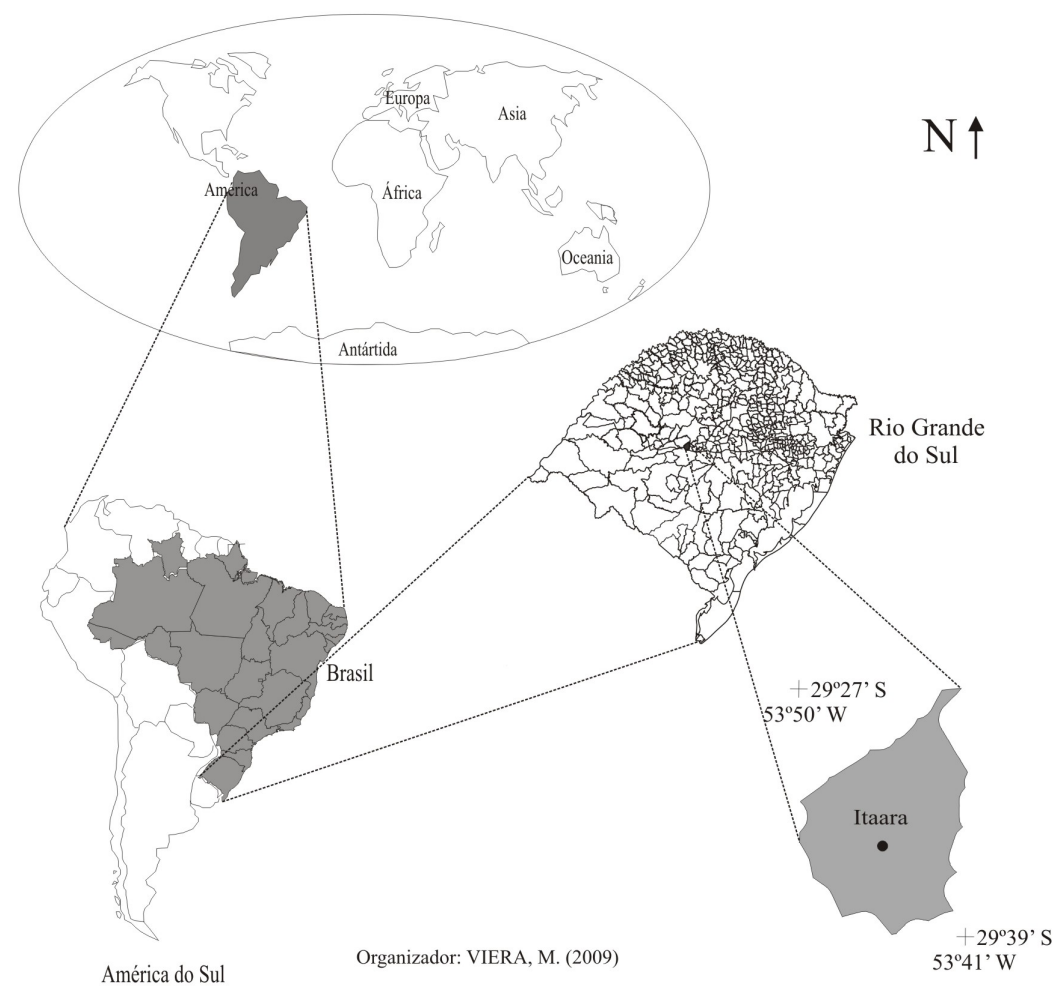

FIGURA 1: Croqui de localização do município de Itaara, RS.

FIGURE 1: Location of Itaara, RS state.

brasiliensis Marchand, Lithraea molleoides (Vell.) Engl., Luhea divaricata Mart. et Zucc., Matayba eleagnoides Radlk., Nectandra megapotamica (Spreng.) Mez, Ocotea puberula (Rich.) Ness, Ocotea pulchella (Nees) Mez, Parapiptadenia rigida (Benth.) Brenan, Cordia americana (L.) Gottschling \& J. S Mill., Quillaja brasiliensis (A. St.-Hil. \& Tul.) Mart., Sebastiania brasiliensis Spreng. e Sebastiania commersoniana (Baill.) L. B. Sm. et Downs, entre outras. Vogel (2005) salienta que no local existem indícios que a área já tenha sido explorada (derrubada e queima da vegetação) possivelmente para o cultivo agrícola. Essa verificação foi possível devido à presença de cepas queimadas e cepas ramificadas.

\section{Metodologia}

Para a realização do presente estudo, foram demarcadas seis parcelas de formato retangular, medindo $25,0 \mathrm{~m}$ x 17,0 m cada, alocadas no interior da floresta de forma sistemática e equidistantes 30 metros, conforme especificações de Péllico Netto e Brena (1997). Em cada uma das parcelas foram instalados cinco coletores. A amostragem da serapilheira foi realizada através de coletores metálicos circulares com $0,50 \mathrm{~m}$ de diâmetro, fixados a um metro de distancia do solo. Nesta estrutura metálica foi aderida tela tipo sombrite (malha 2,0 $\mathrm{mm}$ ), com $30 \mathrm{~cm}$ de profundidade. Mensalmente, entre janeiro de 2006 a dezembro de 2007, foi realizada a coleta do material depositado dentro dos coletores.

Em laboratório, todo o material foi separado nas frações folhas, galhos finos (diâmetro $<0,5 \mathrm{~cm}$ ) e miscelânea (flores, frutos, sementes e restos vegetais não identificáveis). Além disso, a fração folhas foi separada em nível de espécie com maior biomassa presente nos coletores e de possível identificação como o Angico-vermelho (Parapiptadenia rigida), Aroeira (Lithraea molleoides) Camboatá-branco (Matayba elaeagnoides), Camboatá-vermelho (Cupania vernalis), Canela-guaicá (Ocotea puberula), Canela-lageana (Ocotea pulchella), Canela-preta (Nectandra megapotamica), ao nível de família para as Fabaceae, e as demais foram classificadas como "outras".

Após o fracionamento e separação, cada amostra foi posta a secar em estufa de circulação e renovação de ar a uma temperatura de $70{ }^{\circ} \mathrm{C}$ por 72 horas. Posteriormente, procedeu-se a pesagem em balança digital de precisão para a determinação do peso seco. 
Na Tabela 1, verificam-se os valores mensais de pluviosidade ( $\mathrm{mm}$ ), obtidos através da instalação de pluviômetros próximos a floresta em estudo; a temperatura média do $\operatorname{ar}\left({ }^{\circ} \mathrm{C}\right)$ e a umidade relativa do ar (\%), ambos obtidos na estação meteorológica do Instituto Nacional de Pesquisas Espaciais (INPE), localizada no município de São Martinho da Serra-RS, município limítrofe ao do presente estudo, em área com altitude semelhante.

A partir dos dados provenientes da coleta mensal de serapilheira, foram estimadas as quantidades de folhas depositadas mensalmente e anualmente por cada espécie e quantidade total para toda a floresta. Para a análise de correlação de PEARSON (r) entre a deposição de serapilheira e variáveis climáticas ao nível de $5 \%$ e $1 \%$ de significância, utilizou-se o programa estatístico Genes (CRUZ, 2001).

\section{RESULTADOS E DISCUSSÃO}

A deposição média anual de serapilheira, durante o período de estudo (Tabela 2), foi de 5,85 $\mathrm{Mg} \mathrm{ha}^{-1}$ ano ${ }^{-1}$, sendo composta por $63,2 \%$ de folhas, $19,6 \%$ de miscelânea e $17,1 \%$ de galhos finos. As folhas normalmente constituem a maior proporção da biomassa de serapilheira que caem ao solo, ficando geralmente entre 60 a $80 \%$ do total como verificado por Bray e Ghoran (1964) em diferentes formações florestais do mundo, por Toledo e Pereira (2004) em florestas secundárias de Mata Atlântica; por Backes et al. (2005) em Floresta Ombrófila Mista; por Pires et al. (2006) em uma formação de restinga; por Fernandes et al. (2007) em manguezais e por Pereira et al. (2008) em Mata Atlântica.

A deposição total de serapilheira encontrada no presente estudo foi inferior ao observado por outros autores, em floresta Estacional Decidual no

TABELA 1: Valores mensais das variáveis meteorológicas durante o período de estudo.

TABLE 1: Monthly values of the weather variants during the study period.

\begin{tabular}{|c|c|c|c|c|c|c|c|c|c|c|c|c|c|}
\hline Variáveis & Ano & Jan & Fev & Mar & Abr & Mai & Jun & Jul & Ago & Set & Out & Nov & Dez \\
\hline \multirow{2}{*}{$\begin{array}{l}\text { Pluviosidade } \\
\text { (mm) }\end{array}$} & 2006 & 114,9 & 89,3 & 134,5 & 76,9 & 68,0 & 67,8 & 120,2 & 68,0 & 167,6 & 157,0 & 159,2 & 48,4 \\
\hline & 2007 & 146,0 & 207,2 & 149,6 & 75,4 & 148,3 & 110,1 & 124,1 & 53,5 & 224,6 & 126,3 & 102,2 & 127,3 \\
\hline \multirow{2}{*}{$\begin{array}{c}\text { Temperatura } \\
\left({ }^{\circ} \mathrm{C}\right)\end{array}$} & 2006 & 23,3 & 21,9 & 21,6 & 17,9 & 12,8 & 13,8 & 15,2 & 13,7 & 14,1 & 18,8 & 19,3 & 23,0 \\
\hline & 2007 & 22,6 & 22,5 & 22,2 & 19,6 & 12,5 & 13,3 & 9,8 & 11,5 & 17,4 & 18,5 & 18,3 & 22,4 \\
\hline \multirow{2}{*}{ UR (\%) } & 2006 & 85,5 & 84,1 & 83,8 & 84,3 & 90,1 & 93,4 & 89,0 & 81,1 & 85,2 & 86,7 & 80,6 & 82,0 \\
\hline & 2007 & 88,7 & 85,3 & 93,3 & 89,1 & 91,0 & 85,6 & 86,2 & 91,8 & 87,7 & 92,6 & 77,9 & 77,1 \\
\hline
\end{tabular}

TABELA 2: Deposição média anual $\left(\mathrm{kg} \mathrm{ha}^{-1}\right)$ de serapilheira das espécies encontradas em uma Floresta Estacional Decidual.

TABLE 2: Annual average of litter deposition $\left(\mathrm{kg} \mathrm{ha}^{-1}\right)$ from the species found in the Seasonal Deciduous Forest.

\begin{tabular}{|c|c|c|c|c|}
\hline Espécies & Ano $1^{\mathrm{A}}$ & Ano 2 & Média & Total \\
\hline Parapiptadenia rigida & $967,4^{(24,8 / 15,4) \mathrm{B}}$ & $1.032,7^{(29,5 / 19,1)}$ & $1.000,0^{(27,0 / 17,1)}$ & $2.000,1$ \\
\hline Ocotea pulchella & $528,2^{(13,5 / 8,4)}$ & $344,1^{(9,8 / 6,4)}$ & $436,2^{(11,8 / 7,5)}$ & 872,3 \\
\hline Nectandra megapotamica & $122,7^{(3,1 / 1,9)}$ & $156,3^{(4,5 / 2,9)}$ & $139,5^{(3,8 / 2,4)}$ & 279,0 \\
\hline Ocotea puberula & $182,3^{(4,7 / 2,9)}$ & $213,4^{(6,1 / 3,9)}$ & $197,9^{(5,3 / 3,4)}$ & 395,7 \\
\hline Matayba elaeagnoides & $386,6^{(9,9 / 6,1)}$ & $188,3^{(5,4 / 3,5)}$ & $287,5^{(7,8 / 4,9)}$ & 574,9 \\
\hline Cupania vernalis & $119,9^{(3,1 / 1,9)}$ & $128,1^{(3,7 / 2,4)}$ & $124,0^{(3,4 / 2,1)}$ & 248,0 \\
\hline Lithraea molleoides & $145,4^{(3,7 / 2,3)}$ & $150,8^{(4,3 / 2,8)}$ & $148,1^{(4,0 / 2,5)}$ & 296,2 \\
\hline Família Fabaceae ${ }^{\mathrm{C}}$ & $102,2^{(2,6 / 1,6)}$ & $111,0^{(3,2 / 2,1)}$ & $106,6^{(2,9 / 1,8)}$ & 213,2 \\
\hline Outras & $1.349,0^{(34,6 / 21,4)}$ & $1.171,0^{(33,5 / 21,7)}$ & $1.260,0^{(34,1 / 21,5)}$ & $2.520,0$ \\
\hline Folhas $^{\mathrm{D}}$ & $3.903,7^{(100,0 / 62,0)}$ & $3.495,7^{(100,0 / 64,7)}$ & $3.699,8^{(100,0 / 63,2)}$ & $7.399,4$ \\
\hline Galhos finos & $1.221,8^{(19,4)}$ & $783,6^{(14,5)}$ & $1.002,7^{(17,1)}$ & $2.005,5$ \\
\hline Miscelânea & $1.169,0^{(18,6)}$ & $1.127,8^{(20,9)}$ & $1.148,4^{(19,6)}$ & $2.296,9$ \\
\hline Total & $6.294,5^{(100,0)}$ & $5.407,1^{(100,0)}$ & $5.850,9^{(100,0)}$ & $11.701,8$ \\
\hline
\end{tabular}

Em que: ${ }^{\mathrm{A}}$ Ano 1 = janeiro a dezembro de 2006; Ano 2 = janeiro a dezembro de 2007. ${ }^{\mathrm{B}}$ Valores entre parênteses e em sobrescrito, referem-se ao percentual de cada espécie em relação ao total da fração folhas e para o total na serapilheira. ${ }^{\mathrm{C}}$ Espécies da família Fabaceae que foram possíveis de separação. ${ }^{\mathrm{D}}$ Folhas = Deposição total dessa fração. 
Rio Grande do Sul (CUNHA et al., 1993; CUNHA, 1997; BRUN et al., 1999; KÖNIG et al., 2002), que obtiveram produção até superiores a $9,0 \mathrm{Mg} \mathrm{ha}^{-1}$ ano $^{-1}$, justificando-se as diferenças pela idade das florestas, variações de ambiente e, possivelmente, intervenções antrópicas.

A deposição de folhas pelas espécies Parapiptadenia rigida, Ocotea pulchella e Matayba elaeagnoides, juntas chegam a cerca de $30 \%$ do total de serapilheira depositada. No estudo de Cunha (1997), as espécies mais importantes na deposição de folhedo foram as de maior dominância e densidade, algumas delas iguais as deste estudo (Parapiptadenia rigida, Ocotea puberula, Nectranda megapotamica e Cupania vernalis). Esse autor destaca, ainda, que florestas dominadas por poucas espécies, como a Floresta Estacional Decidual na região central do Rio Grande do Sul, têm sua deposição de serapilheira controlada pela fenologia dessas poucas espécies que, portanto possuem um papel decisivo no equilíbrio destes ecossistemas.

As maiores deposições de folhas (Figura 2) ocorreram no período de maio a julho e de setembro a novembro, com os maiores picos nos meses de junho e setembro (460 e $450 \mathrm{~kg} \mathrm{ha}^{-1} \mathrm{ano}^{-1}$, respectivamente). Já a fração galhos finos, mantevese relativamente constante de janeiro a agosto, tendo uma elevação acentuada em setembro (170 $\mathrm{kg} \mathrm{ha}^{-1}$ ano $^{-1}$ ), nos meses seguintes continuou com alta deposição corroborando com os resultados de König et al. (2002) e Vital et al. (2004), cujos autores ressaltam ser uma estratégia típica de florestas estacionais deciduais eliminarem a folhagem senescente visando o novo período de crescimento que se inicia na primavera com a emissão de nova folhagem. A deposição de serapilheira continuou alta e no mês de dezembro voltou ao patamar inicial. Para a miscelânea, pode-se verificar que a mesma segue padrões diferentes das demais frações, sendo, provavelmente, influenciada pelos períodos de floração e frutificação das espécies de maior frequência na área.

É importante observar que a deposição das espécies é bastante variável durante os meses do ano, por exemplo, a Parapiptadenia rigida teve seu pico nos meses de junho e julho, chegando a representar mais de $215 \mathrm{~kg} \mathrm{ha}^{-1}$ mês $^{-1}$ de folhas depositadas ao solo. Essa espécie é caducifólia, começando a perder maior quantidade de massa foliar no inicio do inverno, o mesmo ocorrendo para as espécies da família Fabaceae que foram separadas. Porém, mesmo ocorrendo a perda das folhas em certa época, as espécies caducifólias apresentam contribuições relativamente contínuas durante o ano, isso demonstra uma característica das espécies quanto à persistência de certa percentagem das folhas na copa por período considerável, caindo estas em função de ventos e precipitação.

A Ocotea pulchella, por sua vez, teve os maiores aportes nos meses de outubro e novembro, Matayba elaeagnoides nos meses de setembro e outubro e as demais espécies analisadas seguiram essa mesma tendência, de maiores deposições a partir de setembro. Já, as folhas das espécies não classificadas ("outras"), apresentaram dois períodos distintos de maior deposição, um de abril a junho e o outro nos meses de setembro e outubro.

A deposição de folhas das espécies estudadas em separado segue um comportamento fenológico bem definido, havendo dois períodos de maior deposição, um no outono e início do inverno para espécies caducifólias (Parapiptadenia rigida

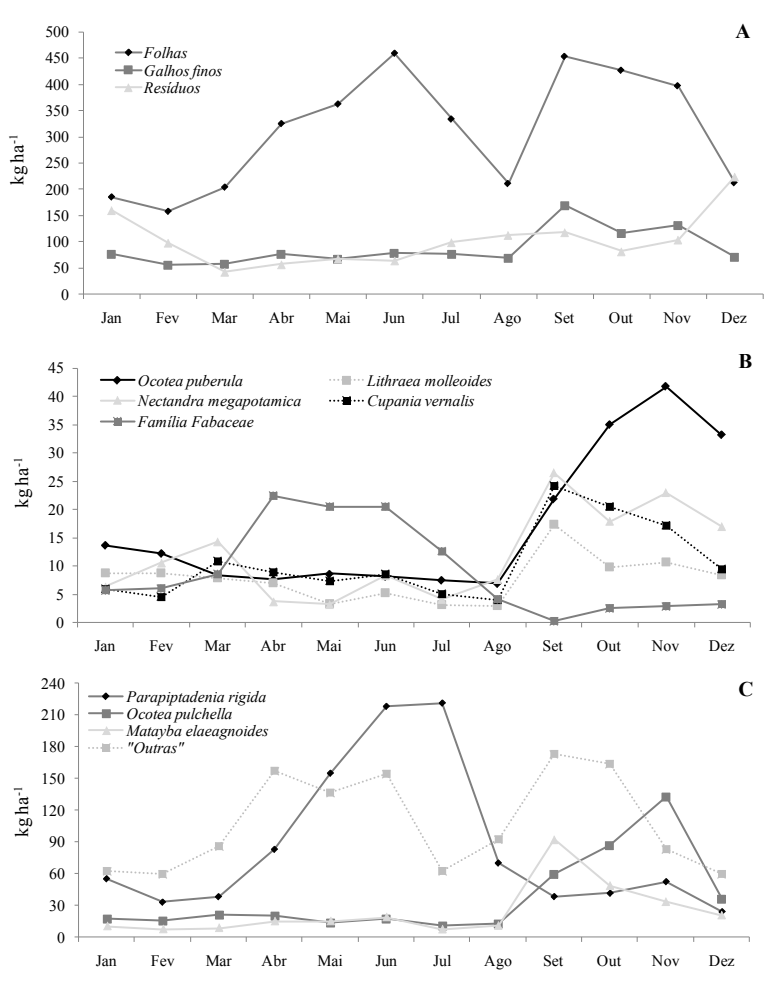

FIGURA 2: Sazonalidade da deposição das frações folhas, galhos finos, miscelânea (A) e folhas das diferentes espécies (B e C).

FIGURE 2: Seasonal deposition of leaves, thin branches, miscellaneous (A) and leaves in the different species (B and C). 
e algumas espécies da família Fabaceae), e outro na saída do inverno e início da primavera, para as demais. Esse pico de deposição de serapilheira na primavera foi verificado por Cunha (1997) e Brun et al. (1999) em diferentes fases sucessionais de Floresta Estacional Decidual e Figueiredo Filho et al. (2003) em Floresta Ombrófila Mista. A variação na deposição de serapilheira pode ser atribuída a vários fatores como: diferentes características genéticas de cada espécie, tipo de sítio, idade da floresta, densidade de indivíduos, estágio sucessional, características edafo-climáticas, estabilidade alcançada pela floresta, dentre outros (FIGUEIREDO FILHO et al., 2003; MOREIRA e SILVA, 2004; FERNANDES et al., 2007; CALDEIRA et al., 2008).

A deposição de folhas da Lithraea molleoides, Cupania vernalis, Nectandra megapotamica e Matayba elaeagnoides aumentou significativamente com o aumento da pluviosidade, durante os dois anos de estudo (Tabela 3). Isto demonstra que estas espécies têm, em parte, a sua perda de folhas regulada pela intensidade das chuvas, situação também constatada por Cunha (1997) quando associada à temperatura em elevação.

Considerando, apenas a fração folhas, sem a separação por espécies, não se obteria correlação significativa, devido à irregularidade de deposição entre as espécies. Brun et al. (2001), König et al. (2002) e Vogel et al. (2007), também em Floresta Estacional Decidual, não encontraram correlações significativas entre a deposição de serapilheira e a pluviosidade, mas em ambos os estudos não houve separação do material senescente por espécie.

A temperatura média mensal do ar foi um dos principais fatores a regular a deposição de folhas da Parapiptadenia rigida, apresentando alta correlação negativa em todo o período. Sendo atribuído a ela ser uma espécie caducifólia, e com a diminuição da temperatura no final do outono e no inverno, a mesma inicia um processo acelerado de deposição de serapilheira. A fração folhas, de forma geral, apresentou correlação negativa com a temperatura média do ar, corroborando com König et al. (2002) em Floresta Estacional Decidual, os quais encontraram correlação de $-0,52(\mathrm{p}<0,05)$, Vogel et al. (2007) também encontrou correlação negativa, mas não significativa. A umidade relativa do ar, também influenciou significativamente na deposição de serapilheira para a Parapiptadenia rigida no primeiro ano de estudo $(\mathrm{r}=-0,79 ; \mathrm{p}<$ $0,01)$ e para as "outras" (espécies não classificadas) de forma geral durante o período de estudo $(\mathrm{r}=$ $0,48 ; \mathrm{p}<0,05)$.

TABELA 3: Coeficiente de correlação de PEARSON (r) entre a deposição de serapilheira e as variáveis meteorológicas.

TABLE 3: PEARSON's correlation ( $\mathrm{r}$ ) coefficient of the litter deposition and the meteorological variables.

\begin{tabular}{|c|c|c|c|c|c|c|c|c|c|}
\hline \multirow{2}{*}{ Espécie } & \multicolumn{3}{|c|}{ Pluviosidade } & \multicolumn{3}{|c|}{ Temperatura do ar } & \multicolumn{3}{|c|}{ Umidade relativa do ar } \\
\hline & Ano1 & Ano2 & Total & Ano1 & Ano2 & Total & Ano1 & Ano2 & Total \\
\hline 1 & $-0,34^{\mathrm{ns}}$ & $-0,29$ ns & $-0,25$ ns & $-0,67 *$ & $-0,76 * *$ & $-0,72 * *$ & $-0,79 * *$ & 0,05 ns & $0,30^{\mathrm{ns}}$ \\
\hline 2 & 0,57 ns & $0,13^{\mathrm{ns}}$ & $0,38^{\mathrm{ns}}$ & $0,2^{\mathrm{ns}}$ & $0,15^{\mathrm{ns}}$ & 0,19 ns & $-0,37^{\mathrm{ns}}$ & $-0,17$ ns & $-0,27$ ns \\
\hline 3 & $0,60 *$ & 0,39 ns & $0,55 * *$ & $-0,05$ ns & $0,52^{\mathrm{ns}}$ & 0,29 ns & $-0,07 \mathrm{~ns}$ & $-0,36^{\mathrm{ns}}$ & $-0,23$ ns \\
\hline 4 & $0,36^{\mathrm{ns}}$ & 0,01 ns & $0,20^{\mathrm{ns}}$ & $0,31^{\mathrm{ns}}$ & 0,41 ns & 0,35 ns & $-0,42$ ns & $-0,41^{\mathrm{ns}}$ & $-0,37^{\text {ns }}$ \\
\hline 5 & $0,60 *$ & 0,50 ns & $0,50 *$ & $-0,16^{\text {ns }}$ & $-0,02$ ns & $-0,06^{\mathrm{ns}}$ & $-0,04$ ns & $0,06^{\mathrm{ns}}$ & $-0,04$ ns \\
\hline 6 & $0,68 *$ & 0,44 ns & $0,65 * *$ & $0,05^{\text {ns }}$ & 0,20 ns & 0,10 ns & $-0,13^{\mathrm{ns}}$ & 0,02 ns & $-0,03$ ns \\
\hline 7 & $0,60 *$ & $0,68 *$ & $0,66 * *$ & $0,30^{\mathrm{ns}}$ & 0,44 ns & $0,37^{\text {ns }}$ & $-0,24$ ns & $-0,03$ ns & $-0,08$ ns \\
\hline 8 & $-0,48^{\mathrm{ns}}$ & $-0,21$ ns & $-0,31$ ns & $-0,19$ ns & $-0,61 *$ & $-0,40^{\mathrm{ns}}$ & $0,30^{\mathrm{ns}}$ & 0,19 ns & 0,24 ns \\
\hline 9 & $0,27^{\text {ns }}$ & $-0,11$ ns & $0,10^{\mathrm{ns}}$ & $-0,59 *$ & $-0,08$ ns & $-0,31^{\mathrm{ns}}$ & $0,38^{\text {ns }}$ & $0,61 *$ & $0,48 *$ \\
\hline 10 & $0,41^{\mathrm{ns}}$ & $-0,05$ ns & $0,26^{\mathrm{ns}}$ & $-0,43^{\text {ns }}$ & $-0,53^{\text {ns }}$ & $-0,46 *$ & 0,29 ns & 0,22 ns & $0,24{ }^{\mathrm{ns}}$ \\
\hline 11 & $0,71 * *$ & $0,16^{\text {ns }}$ & $0,41^{\mathrm{ns}}$ & $-0,32$ ns & 0,38 ns & $-0,10^{\mathrm{ns}}$ & $-0,08$ ns & 0,20 ns & $-0,05$ ns \\
\hline 12 & $0,01^{\text {ns }}$ & $-0,17$ ns & $-0,05$ ns & $0,60 *$ & $-0,29$ ns & 0,20 ns & $-0,40^{\text {ns }}$ & $-0,12^{\mathrm{ns}}$ & $-0,24^{\mathrm{ns}}$ \\
\hline Total & 0,50 ns & $-0,10^{\text {ns }}$ & $0,30^{\mathrm{ns}}$ & $-0,18$ ns & $-0,60$ ns & $-0,29 \mathrm{~ns}$ & 0,03 ns & 0,20 ns & 0,07 ns \\
\hline
\end{tabular}

Em que: 1 = Parapiptadenia rigida $; 2=$ Ocotea pulchella $; 3=$ Nectandra megapotamica $; 4=$ Ocotea puberula $; 5=$ Matayba elaeagnoides; $6=$ Cupania vernalis; $7=$ Lithraea molleoides; $8=$ Família Fabaceae; $9=$ Outras; $10=$ Folhas; 11 = Galhos finos; 12 = Miscelânea. * = Correlação significativa ao nível de 5\% de significância; ** = Correlação significativa ao nível de $1 \%$ de significância; ${ }^{\text {ns }}=$ Correlação não significativa.

Ci. Fl., v. 21, n. 3, jul.-set., 2011 
König et al. (2002) não encontrou pontos altos de coincidência entre a deposição de serapilheira e as altas precipitações, porém Cunha et al. (1993) verificou que as menores deposições de serapilheira foram encontradas no outono e as maiores na primavera, período em que a temperatura média mensal estava em elevação e as precipitações mensais foram abundantes. Martins e Rodrigues (1999) estudando deposição de serapilheira em Floresta Estacional Semidecidual encontraram correlações de moderadas a fracas $(\mathrm{r} \leq$ $0,50)$ destacando-se que as deposições da capoeira, do capoeirão e da floresta secundária, foram influenciadas positivamente pela velocidade média dos ventos e pela umidade relativa do ar.

\section{CONCLUSÕES}

A deposição de folhas das espécies segue um comportamento fenológico bem definido, havendo dois períodos de maior deposição, um no outono e início do inverno para as espécies caducifólias, e outro na saída do inverno e início da primavera, para as demais espécies;

Parapiptadenia rigida, Ocotea pulchella e Matayba elaeagnoides, são as principais espécies em devolução de serapilheira (cerca de $30 \%$ do total);

A deposição de folhas da Lithraea molleoides, Cupania vernalis, Nectandra megapotamica e Matayba elaeagnoides aumentaram significativamente com o aumento da pluviosidade assim como a da Parapiptadenia rigida com a diminuição da temperatura do ar.

\section{AGRADECIMENTOS}

Os autores agradecem a Brigada Militar do Estado do Rio Grande do Sul por ceder a área em que foi realizado o presente estudo, localizada no Centro de Estudos e Treinamento, Reprodução Animal e Proteção Ambiental (CETRAPA) no município de Itaara-RS.

\section{REFERÊNCIAS BIBLIOGRÁFICAS}

AGRITEMPO - Sistema de Monitoramento Agrometeorológico. Disponível em: $<$ (http://www. agritempo.gov.br/agroclima/sumario? $\mathrm{uf}=\mathrm{RS}$ ) $>$ Acesso em: 11 de junho de 2010.

ANDRADE, A. G.; COSTA, G. S.; FARIA, S. M. Deposição e decomposição da serapilheira em povoamentos de Mimosa caesalpiniifolia, Acacia manguim e Acacia holosericea com quatro anos de idade em planossolo. Revista Brasileira de Ciência do Solo, Viçosa, v. 24, n. 4, p. 777-785, out./nov. 2000.

BACKES, A.; PRATES, F. L.; VIOLA, M. G. Produção de serapilheira em Floresta Ombrófila Mista, em São Francisco de Paula, Rio Grande do Sul, Brasil. Acta Botânica Brasilica, São Paulo, v. 19, n. 1, p. 155-160, jan./mar. 2005.

BRAY, J. R.; GHORAN, E. Litter production in forest of the world. Londres: Advances in Ecological Research, 1964. p.101-157.

BRUN, E. J. et al. Produção de serapilheira e devolução de nutrientes em três fases sucessionais de uma Floresta Estacional Decidual no município de Santa Tereza-RS. In: SIMPÓSIO SOBRE FERTILIZAÇÃO E NUTRIÇÃO FLORESTAL, 1999, Piracicaba. Anais... Piracicaba: IPEFESALQ/USP, 1999. p.348-364.

BRUN, E. J. et al. Relação entre a produção de serapilheira e variáveis meteorológicas em três fases sucessionais de uma floresta estacional decidual no Rio Grande do Sul. Revista Brasileira de Agrometeorologia, Santa Maria, v. 9, n. 2, p. 277-285, jul./dez. 2001.

CALDEIRA, M. V. W. et al. Quantificação de serapilheira e de nutrientes em uma Floresta Ombrófila Densa. Semina: Ciências Agrárias, Curitiba, v. 29, n. 1, p. 53-68, jan./mar. 2008.

CRUZ, C. D. Programa Genes - Aplicativo Computacional em Genética e estatística. Versão 2001.0.0 for Windows, 2001.

CUNHA, G. C. Aspectos da Ciclagem de nutrientes em diferentes fases sucessionais de uma Floresta Estacional do Rio Grande do Sul. 1997. 86 f. Dissertação (Mestrado em Engenharia Florestal) - ESALQ/Escola Superior de Agricultura "Luiz de Queiroz", Piracicaba, 1997.

CUNHA, G. C. et al. Dinâmica nutricional em Floresta Estacional Decidual com ênfase aos minerais provenientes da deposição da serapilheira. Ciência Florestal, Santa Maria, v. 3, n. 1, p. 35-64, jan./dez. 1993.

FERNANDES, M. E. B.; NASCIMENTO, A. A. M.; CARVALHO, M. L. Estimativa da produção anual de serapilheira dos bosques de Mangue no Furo Grande, Bragança-Pará. Revista Árvore, Viçosa, v. 31, n. 5, p. 949-958, set./dez. 2007.

FERREIRA, R. L. C. et al. Deposição e acúmulo de matéria seca e nutrientes em serapilheira em um bosque de sabiá (Mimosa caesalpiniifolia benth.). 
Revista Árvore, Viçosa, v. 31, n. 1, p. 7-12, jan./ fev. 2007.

FIGUEIREDO FILHO, A. et al. Avaliação Estacional da Deposição de Serapilheira em uma Floresta Ombrófila Mista Localizada no Sul do Paraná. Ciência Florestal, Santa Maria, v. 13, n. 1, p. 11-18, jan./jun. 2003.

KÖNIG, F. G. et al. Avaliação da sazonalidade da produção de serapilheira numa floresta Estacional Decidual no município de Santa Maria-RS. Revista Árvore, Viçosa, v. 26, n. 4, p. 429-435, jul./ago. 2002.

LONGHI, S. J. et al. Composição florística e estrutura da comunidade arbórea de um fragmento florestal no município de Santa Maria-Brasil. Ciência Florestal, Santa Maria, v. 9, n. 1, p. 115133, jan./ jun. 1999.

LONGHI, S. J.; GREFF, L. T. B. Distribuição de espécies arbóreas em relação a parâmetros ambientais em uma Floresta Estacional Decidual no município de Itaara, RS. Santa Maria: UFSM, 2006. 16 p. (Relatório de Iniciação Científica (CNPq/Pibic)

MARTINS, S. V.; RODRIGUES, R. R. Produção de serapilheira em clareiras de uma Floresta Estacional Semidecidual no município de Campinas, SP. Revista Brasileira de Botânica, São Paulo, v. 22, n. 3, p. 405-412, set./dez. 1999.

MOREIRA, P. R.; SILVA, O. A. Produção de serapilheira em área reflorestada. Revista Árvore, Viçosa, v. 28, n. 1, p. 49-59, jan./mar. 2004.

MORENO, J. A. Clima do Rio Grande de Sul. Porto Alegre: Secretaria da Agricultura, 1961. 83 p. OLSON, J. S. Energy storage and the balance of producers and decomposers in ecological systems. Ecology, Durham, v. 44, n. 2, p. 322-330, mar./maio 1963.

OLIVEIRA, R. R. Produção e decomposição de serapilheira no Parque Nacional da Tijuca, RJ. 1987. 107 f. Dissertação (Mestrado em Geografia) - Departamento de Geografia. Instituto de Geociências, 1987.
PÉLLICO NETTO, S.; BRENA, D. A. Inventário Florestal. Curitiba: Editado pelos autores, 1997, $315 \mathrm{p}$.

PEREIRA, M. G.; MENEZES, L. F. T.; SCHULTZ, N. Aporte e decomposição da serapilheira na Floresta Atlântica, Ilha da Marambaia, Mangaratiba, RJ. Ciência Florestal, Santa Maria, v. 18, n. 4, p. 443-454, out./dez.2008.

PIRES, L. A. et al. Produção, acúmulo e decomposição da serapilheira em uma restinga da Ilha do Mel, Paranaguá, PR, Brasil. Acta Botânica Brasilica, São Paulo, v. 20, n. 1, p. 173-184, jan./ mar. 2006.

POGGIANI, F.; SCHUMACHER, M. V. Nutrient cycling in native forests. In: GONÇALVES, J. L. M.; BENEDETTI, V. Eds. Forest nutrition and fertilization. 2nd ed. Piracicaba: IPEF, 2004. p. 285-306.

RIO GRANDE DO SUL. Governo do Estado. Secretaria Estadual do Meio Ambiente. Inventário Florestal Contínuo do Rio Grande do Sul. 2002. Disponível em: <www.ufsm.br/ifcrs>. Acesso em 15 de Setembro de 2008.

STRECK, E. V. et al. Solos do Rio Grande do Sul. 2. ed. Porto Alegre: EMATER/RS, 2008. 222 p.

TOLEDO, L. O.; PEREIRA, M. G. Dinâmica da deposição de serapilheira em florestas secundárias do município de Pinheiral, RJ. Floresta e Ambiente, Rio de Janeiro, v. 11, n. 1, p. 39-46, jan./jun. 2004. VITAL, A. R. T. et al. Produção de serapilheira e ciclagem de nutrientes de uma floresta estacional semidecidual em zona ripária. Revista Árvore, Viçosa, v. 28, n. 6, p. 793-800, nov./dez. 2004.

VOGEL, H. L. M. Quantificação da biomassa e nutrientes em uma floresta Estacional Decidual em Itaara-RS, Brasil. 2005. 94 f. Tese (Doutorado em Engenharia Florestal) - Universidade Federal de Santa Maria, Santa Maria, 2005.

VOGEL, H. M. et al. Avaliação da devolução de serapilheira em uma floresta Estacional Decidual em Itaara, RS, Brasil. Ciência Florestal, Santa Maria, v. 17, n. 3, p. 187-196, jul./set. 2007. 